\title{
More worries about pollution
}

Recent events notwithstanding, significant problems lie ahead from increasing concentrations of some constituents of the lower atmosphere. Solutions depend not only on regulation but also on changes in the way environmental science is supported.

THERE is a gas in the troposphere - the lowest $10 \mathrm{~km}$ or so of the atmosphere - that is worth singling out. Its background levels in the Northern Hemisphere have doubled over this century, and are now so high that fluctuations frequently take concentrations over health and other damage thresholds. Much of its chemistry is quite well understood, but there are significant uncertainties about its behaviour - its distribution around the globe and associated longterm tends, and factors underlying them. What is more, it neatly exemplifies a problem in the conduct of environmental research associated with developing countries.

The gas in question, ozone, is more famous for its diminishing presence above the troposphere. In fact the global ozone cycle includes transport between the stratosphere and troposphere, which can occasionally give rise to sudden increases at ground level. But the primary tropospheric processes are chemical and photochemical, involving sunlight as well as ozone's primary precursors: nitrogen oxides and volatile organic compounds. As in the stratosphere, ozone itself is not the villain of the piece. In the lower atmosphere, however, problems arise not from chlorofluorocarbon refrigerants but from road transport, industrial solvents and paints, increasing use of fertilizers with population growth, and - in the tropics - biomass burning.

Episodes in which ozone is temporarily enhanced - photochemical smog - have long been notorious in Los Angeles, where reactants are trapped by the topography. Similar immobile pollution arises in Athens, for example. In windier regions to the north, reactions are instigated in cities but, due to their slowness, typically bring about enhanced ozone levels in their host airmasses as they travel well away from the source. That brings about high ozone concentrations in rural areas which, increasingly, are damaging crops. And, whether in cities or downwind of them, periods of human exposure to levels above those readily tolerated by the World Health Organisation are growing both in duration and frequency, giving rise to increased bronchial illness.

A meeting two weeks ago of environment ministers from northwest Europe was the first time that tropospheric ozone received concerted attention at such a high political level. For them, episodic enhancements are a problem of both atmospheric transport and scientific collaboration across national boundaries. In the event they produced only words: requests that the United Nations and the European Union make rapid progress towards abatement protocols, and agreement to cooperate in exchanging data for forecasts. Their difficulty is that abatement involves not only technological fixes to vehicle emissions, which are relatively straightforward, but also, and much more politically challenging, restrictions on the use of road transport. Only when damage to health and national wealth climbs significantly higher, it seems, are citizens or politicians going to grasp the latter nettle.

To reduce the background concentrations is a hemispheric problem. The United Nations and the European Union are developing emission protocols that should help, provided they have teeth, but there is a scientific issue as well. Ozone contributes to greenhouse warming both directly and through its involvement in the chemistry of one of the most climatically active gases, methane. All the more reason, therefore, that we should know much more than we do about its distribution, particularly in the tropics. To achieve that requires more measurements of ozone and other chemicals. But funding agencies in developed countries will not readily support observing stations in developing ones. At the same time, attempts by distinguished scientists via the UN Environmental Programme (UNEP) to get developing countries and others to stump up, say, US\$5million a year for 25 new monitoring stations have failed to arouse interest among third-world governments.

That is another example of a problem already discussed in these columns (see Nature $\mathbf{3 8 0}, 467 ; 1996$ ): how to overcome institutional and political barriers to fund well distributed measurements of important geophysical and geochemical quantities - a problem, incidentally, that also undermines the ability of the Intergovernmental Panel on Climate Change to be conclusive (see news, page 455). With tropospheric ozone, the right coalition still needs to be found, within UNEP or elsewhere, to bring home the climatic, health and agricultural significance of our ignorance. But found it surely must be.

\section{Watch this boom}

California's links between science, technology and the economy of the state still set the standard for others to follow.

THE Californian economy is roaring ahead, following a five-year relapse which obliged the Golden State - briefly and uncharacteristically - to question its own unique strengths. As a leading economist told a Californian "science and technology summit" last week, the revival is built on science and its application. The new boom is led by information technology, biotechnology and the movie industry. The awesome strength of the first two in the state (see news, page 459) springs from the virtuous cycle of world-beating science, innovative engineering, and access to venture capital.

The significant role of the federal government in all of this is too often forgotten. Being the largest state in the Union - with the largest congressional delegation and a pivotal role in presidential elections - has helped California secure an unequal share of federal R\&D. It has one-eighth of the US population, but gets one-third of NASA's money and a quarter of the Department of Defense's huge research pot. Interestingly, California does less well (fair shares only) when research funds are properly peerreviewed for quality, as at the National Institutes of Health and the National Science Foundation. But it would be churlish to credit federal generosity for creating California's success in applying science and technology: it has merely served to lubricate the energy, imagination and flexibility which characterizes the place.

In the depths of the recession there was some rumbling for a proper "science and technology policy" for California, but that has quietened. All the state needs now is more of the same. Silicon Valley has already engulfed most of the San Francisco Bay area. Its approach will be replicated elsewhere in the state much more readily than it will be in the rest of the world, which should continue, nonetheless, to measure economic success against the model that California provides. 